\title{
GLOBAL GEOID ADJUSTMENT ON LOCAL AREA FOR GIS APPLICATIONS USING GNSS PERMANENT STATION COORDINATES
}

\author{
Ugo FALCHI $^{\mathbb{D}}$, Claudio PARENTE ${ }^{\mathbb{D} *}$, Giuseppina PREZIOSO ${ }^{(\mathbb{D}}$ \\ Dipartimento di Scienze e Tecnologie, Università degli Studi di Napoli "Parthenope", Italy
}

Received 07 August 2018; accepted 20 September 2018

\begin{abstract}
Orthometric heights, useful for many engineering and geoscience applications, can be obtained by GPS (Global Positioning System) surveys only when an accurate geoid undulation model (that supplies the vertical separation between the geoid and WGS84 ellipsoid) is available for the considered topic area. Global geoid height models (i.e., EGM2008), deriving from satellite gravity measurements suitably integrated with other data are free available on web, but their accuracy is often not sufficient for the user's purposes. More accurate local models can nevertheless be acquired, but often only for a fee. GPS/levelling surveys are suitable for determining a local, accurate geoid model, but may be too expensive. This paper aims to demonstrate that GNSS (Global Navigation Satellite System) Permanent Station documents (monographs), freely available on the web and supplying orthometric and ellipsoidal heights, permit to calculate precise geoidal undulations useful to perform global geoid modelling on a local area. In fact, in this study 25 GNSS Permanent Stations (GNSS PS), located in North-Western Italy are considered: the differences between GNSS PS geoidal heights and the corresponding EGM2008 $1^{\prime} \times 1^{\prime}$ ones are used as a starting dataset for Ordinary Kriging applications. The resulting model is summed to the EGM2008 1' $\times 1^{\prime}$, obtaining a better-performed model of the interest area. The accuracy tests demonstrate that the resulting model is better than EGM2008 grids to produce contours from a GPS dataset for large-scale mapping.
\end{abstract}

Keywords: geoid, EGM2008, GNSS Permanent Stations, spatial interpolation, Ordinary Kriging, GIS.

\section{Introduction}

The geoid, namely the shape that the surface of the oceans would take under the influence of Earth's gravity and rotation alone, in the absence of other influences such as tides and winds (Pugh, 1987), is also the reference surface to which levelled heights refer. In fact, the orthometric height $(\mathrm{H})$ of a point is the distance, along a plumb line, from the point to the geoid that is not coincident with the reference ellipsoid of the Earth: the vertical separation between the ellipsoid and the geoid is known as geoid undulation $(\mathrm{N})$. A model giving the relationship between $\mathrm{N}$ and the horizontal location, such as the Easting (x) and Northing (y), is named a geoid model.

The conversion of GPS (Global Positioning System) ellipsoidal height $(\mathrm{h})$ into orthometric height requires a knowledge of the geoid undulation related to WGS84 ellipsoid (Featherstone, Dentith, \& Kirby, 1998; Fotopoulos, Kotsakis, \& Sideris, 2003; Kaplan \& Hegarty, 2005; Shen \& Han, 2013; Pepe, Prezioso, \& Santamaria, 2015). In fact, a WGS84 ellipsoidal height is transformed to an orthometric height by algebraically subtracting the geoid-WGS84 ellipsoid separation using the simple mathematical relation $H=h-N$.

In many engineering and geoscience applications, orthometric height is fundamental, e.g., to build Digital Terrain Models (DTMs) (Maglione, Parente, Santamaria, \& Vallario, 2014), and is useful for geometric correction of high-resolution satellite images (Belfiore \& Parente, 2016) as well as SAR (Synthetic Aperture Radar) image processing (Errico et al., 2014; Di Pasquale, Nico, Pitullo, \& Prezioso, 2018). The OSU91A (Rapp \& Wang, 1993), EGM96 (Lemoine et al., 1998) and EGM2008 (Pavlis, Holmes, Kenyon, \& Factor, 2008), are some of the models used to determine the orthometric height from GPS measurements. However, they are global geopotential models from which geoid height files are extracted, e.g., WGS84 EGM96 15-Minute Geoid Height File is a 15 -minute grid of point values in the tide-free system, using the EGM96 Geopotential Model to degree and order 360 (NGA/NASA, n.d.).

Because an accurate geoid model is essential for determining orthometric heights using GNSS (Global Navigation Satellite System) technology, many researchers

${ }^{\star}$ Corresponding author. E-mail: claudio.parente@uniparthenope.it 
have improved the working efficiency of EGM2008 with the polynomial mathematical model (Peprah, Ziggah, \& Yakubu, 2017). By contrast, local geoid height models with more accurate grid spacing are determined, e.g., using GPS/levelling points, where both the ellipsoidal and orthometric heights are given; the first using GNSS technology, the latter derived from a surveying technique called "precise levelling".

National geoid models are generally derived by a combination of different datasets, integrating individual pure astrogeodetic, gravimetric and GPS/levelling solutions (Marti, 2007). The Italian geoid model, named ITALGEO2005 (Barzaghi, Borghi, Carrion, \& Sona, 2007), is the national gravimetric geoid integrated with GPS/levelling data: it is available with grid spacing of $2^{\prime}$ both in latitude and in longitude; each file, corresponding to an area of $20^{\prime}$ in latitude and $30^{\prime}$ in longitude, is available in return for payment. Because for most Italian GNSS Permanent Stations documents (monographs) containing 3D coordinates (not only latitude/longitude or North and East, but also orthometric and ellipsoidal heights) are available on the Internet, it is possible to use these points to improve the accuracy of EGM2008, determining a geoid model for the local area free of charge.

In this paper the geoid model is determined for an area located in North-western Italy using Ordinary Kriging interpolation applied to a dataset resulting from GNSS Permanent Station monographs.

The paper is organised as follows. Section 1 describes the materials and methods: the horizontal coordinates of the 25 GNSS Permanent Stations (GNSS PS) and the geoid undulation, calculated at these points from the orthometric and ellipsoidal heights, are used to improve the accuracy of the EGM2008 global model. In particular, differences between the GNSS PS geoidal heights and the corresponding EGM2008 $1^{\prime} \times 1^{\prime}$ ones are interpolated using Ordinary Kriging; the resulting values are summed to EGM2008. Section 2 presents and discusses the results. Finally, last section draws some conclusions.

\section{Materials and methods}

\subsection{Study area and GNSS permanent stations}

GNSS positioning services have been rapidly developing in Italy. For administrative reasons public positioning services are designed, created and managed on a local scale, corresponding to the Italian regions (Biagi, Caldera, Capra, Castagnetti, \& Sansò, 2008). In this paper, 25 GNSS Permanent Stations (GNSS PSs) located in in North-western Italy are considered. They are included in the GNSS networks of four regions: Lombardia (5 GNSS PSs), Piemonte (14), Valle d'Aosta (3) and Liguria (3). In reference to WGS84 (ETRF2000) (Van der Marel, 2014; Falchi, 2017), they cover an area of about $28,000 \mathrm{sq} \mathrm{km}$ extending from $44^{\circ} 18^{\prime} 56.59623^{\prime \prime} \mathrm{N}$ to $45^{\circ} 48^{\prime} 7.77740^{\prime \prime} \mathrm{N}$ in latitude and from $7^{\circ} 9^{\prime} 7.75178^{\prime \prime} \mathrm{E}$ to $9^{\circ} 19^{\prime} 24.65950^{\prime \prime} \mathrm{E}$ in longitude. The monographs of all the considered stations are available on the Internet: each of them supplies horizontal coordinates (latitude/longitude, North/East) referred to WGS84 (ETRF2000) and the orthometric and ellipsoidal heights.

The geoid undulation of each station (GSS) is computed subtracting $\mathrm{H}$ from $\mathrm{h}$. Horizontal coordinates (latitude and longitude), for each GNSS Permanent Station are reported in Table 1. Using ArcGIS 10.3 (Environmental

Table 1. The GNSS (Global Navigation Satellite System) Permanent Stations (PS) considered: Italian region, station name, horizontal coordinates (latitude and longitude) are reported

\begin{tabular}{|c|c|c|c|c|}
\hline $\begin{array}{l}\text { Sta- } \\
\text { tion }\end{array}$ & Region & Name & Latitude $(\mathrm{N})$ & Longitude (E) \\
\hline 1 & Liguria & $\begin{array}{l}\text { Cairo } \\
\text { Monte- } \\
\text { notte }\end{array}$ & $44^{\circ} 24^{\prime} 18.9572^{\prime \prime}$ & $8^{\circ} 16^{\prime} 49.7799^{\prime \prime}$ \\
\hline 2 & Liguria & Chiavari & $44^{\circ} 24^{\prime} 9.6273^{\prime \prime}$ & $9^{\circ} 19^{\prime} 24.6595^{\prime \prime}$ \\
\hline 3 & Liguria & Genova & $44^{\circ} 19^{\prime} 13.2549^{\prime \prime}$ & $8^{\circ} 57^{\prime} 33.5961^{\prime \prime}$ \\
\hline 4 & Piemonte & $\begin{array}{l}\text { Ales- } \\
\text { sandria }\end{array}$ & $44^{\circ} 55^{\prime} 23.40849^{\prime \prime}$ & $8^{\circ} 36^{\prime} 58.84354^{\prime \prime}$ \\
\hline 5 & Piemonte & Biella & $45^{\circ} 33^{\prime} 38.67823^{\prime \prime}$ & $8^{\circ} 2^{\prime} 52.98385^{\prime \prime}$ \\
\hline 6 & Piemonte & $\begin{array}{l}\text { Busso- } \\
\text { leno }\end{array}$ & $45^{\circ} 8^{\prime} 12.49356^{\prime \prime}$ & $7^{\circ} 9^{\prime} 7.75178^{\prime \prime}$ \\
\hline 7 & Piemonte & Canelli & $44^{\circ} 43^{\prime} 20.14427^{\prime \prime}$ & $8^{\circ} 17^{\prime} 34.15842^{\prime \prime}$ \\
\hline 8 & Piemonte & $\begin{array}{l}\text { Crescen- } \\
\text { tino }\end{array}$ & $45^{\circ} 11^{\prime} 32.76686^{\prime \prime}$ & $8^{\circ} 6^{\prime} 20.76024^{\prime \prime}$ \\
\hline 9 & Piemonte & Cuorgnè & $45^{\circ} 23^{\prime} 16.47581^{\prime \prime}$ & $7^{\circ} 38^{\prime} 51.71304^{\prime \prime}$ \\
\hline 10 & Piemonte & Demonte & $44^{\circ} 18^{\prime} 56.59623^{\prime \prime}$ & $7^{\circ} 17^{\prime} 33.45928^{\prime \prime}$ \\
\hline 11 & Piemonte & Gozzano & $45^{\circ} 44^{\prime} 48.27063^{\prime \prime}$ & $8^{\circ} 26^{\prime} 0.23103^{\prime \prime}$ \\
\hline 12 & Piemonte & Mondovì & $44^{\circ} 23^{\prime} 25.28474^{\prime \prime}$ & $7^{\circ} 49^{\prime} 44.23858^{\prime \prime}$ \\
\hline 13 & Piemonte & Novara & $45^{\circ} 26^{\prime} 49.9447^{\prime \prime}$ & $8^{\circ} 36^{\prime} 50.26952^{\prime \prime}$ \\
\hline 14 & Piemonte & Ostana & $44^{\circ} 41^{\prime} 32.41281^{\prime \prime}$ & $7^{\circ} 11^{\prime} 18.02539^{\prime \prime}$ \\
\hline 15 & Piemonte & $\begin{array}{l}\text { Savig- } \\
\text { liano }\end{array}$ & $44^{\circ} 38^{\prime} 51.48764^{\prime \prime}$ & $7^{\circ} 39^{\prime} 38.39155^{\prime \prime}$ \\
\hline 16 & Piemonte & $\begin{array}{l}\text { Serravalle } \\
\text { Scrivia }\end{array}$ & $44^{\circ} 43^{\prime} 51.83096^{\prime \prime}$ & $8^{\circ} 51^{\prime} 11.13653^{\prime \prime}$ \\
\hline 17 & Piemonte & Torino & $45^{\circ} 3^{\prime} 48.11252^{\prime \prime}$ & $7^{\circ} 39^{\prime} 40.5996^{\prime \prime}$ \\
\hline 18 & $\begin{array}{l}\text { Valle } \\
\text { d'Aosta }\end{array}$ & Rumiod & $45^{\circ} 43^{\prime} 1.64274^{\prime \prime}$ & $7^{\circ} 11^{\prime} 55.24177^{\prime \prime}$ \\
\hline 19 & $\begin{array}{l}\text { Valle } \\
\text { d'Aosta }\end{array}$ & $\begin{array}{l}\text { Torre di } \\
\text { Nus }\end{array}$ & $45^{\circ} 45^{\prime} 10.39905^{\prime \prime}$ & $7^{\circ} 26^{\prime} 33.45763^{\prime \prime}$ \\
\hline 20 & $\begin{array}{l}\text { Valle } \\
\text { d'Aosta }\end{array}$ & Verres & $45^{\circ} 39^{\prime} 52.81099^{\prime \prime}$ & $7^{\circ} 41^{\prime} 24.65484^{\prime \prime}$ \\
\hline 21 & Lombardia & Como & $45^{\circ} 48^{\prime} 7.7774^{\prime \prime}$ & $9^{\circ} 5^{\prime} 44.22696^{\prime \prime}$ \\
\hline 22 & Lombardia & Milano & $45^{\circ} 28^{\prime} 47.94815^{\prime \prime}$ & $9^{\circ} 13^{\prime} 45.6271^{\prime \prime}$ \\
\hline 23 & Lombardia & Pavia & $45^{\circ} 12^{\prime} 10.732^{\prime \prime}$ & $9^{\circ} 8^{\prime} 10.10416^{\prime \prime}$ \\
\hline 24 & Lombardia & Varzì & $44^{\circ} 49^{\prime} 24.00744^{\prime \prime}$ & $9^{\circ} 11^{\prime} 50.65916^{\prime \prime}$ \\
\hline 25 & Lombardia & Vigevano & $45^{\circ} 18^{\prime} 53.25705^{\prime \prime}$ & $8^{\circ} 51^{\prime} 43.02233^{\prime \prime}$ \\
\hline
\end{tabular}




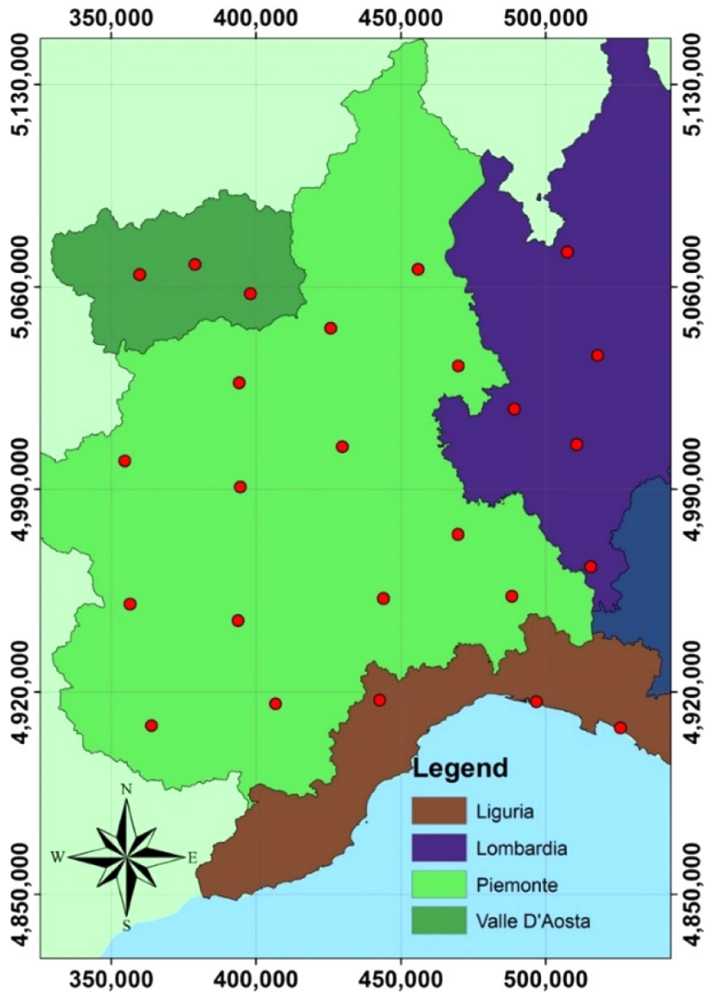

Figure 1. The study area and the 25 GNSS Permanent Stations referred to UTM-WGS84 (ETRF2000) (Universal Transverse Mercator) (horizontal coordinates are in meters)

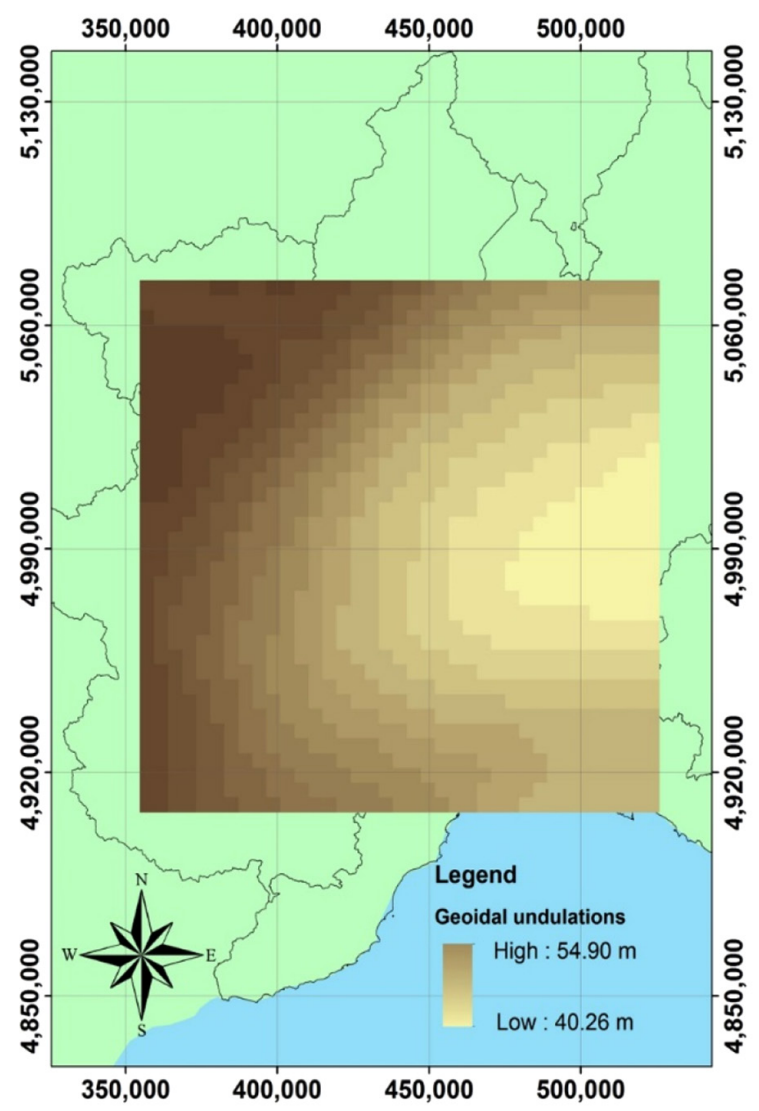

Figure 2. EGM2008 geoid undulations $\left(2.5^{\prime} \times 2.5^{\prime}\right)$ in the considered area (horizontal coordinates are in meters)
Systems Research Institute - ESRI, Redlands, California, USA) the shape file of all 25 stations referred to UTMWGS84 (ETRF2000) (Universal Transverse Mercator) is obtained (Figure 1). The mean distance between the two nearest stations is about $33 \mathrm{~km}$.

\subsection{EGM2008 geoid undulation}

The official Earth Gravitational Model EGM2008 is a spherical harmonic model of the Earth's gravitational potential computed by the National Geospatial-Intelligence Agency (NGA) EGM Development Team. It is a least squares combination of the ITG-GRACE03S gravitational model and its associated error covariance matrix, with the gravitational data obtained from a worldwide set of areamean free-air gravity anomalies defined on a grid spacing of $5^{\prime}$ both in latitude and in longitude.

This grid results as an integration of airborne, terrestrial and altimetry-derived gravity data. EGM2008 is complete to spherical harmonic degree and order 2159 and encloses additional coefficients up to degree 2190 and order 2159 (Pavlis, Holmes, Kenyon, \& Factor, 2012; Barzaghi, Carrion, Pepe, \& Prezioso, 2016).

Full access to the model's coefficients and other descriptive files with additional details about EGM2008 are provided on the Internet. The FORTRAN harmonic synthesis program, hsynth WGS84.f, permits to compute point geoid undulations with respect to WGS84 from spherical harmonic synthesis of the EGM2008 Tide Free Spherical Harmonic Coefficients and its associated Correction Model, at any WGS84 latitude/longitude coordinate pair listed in a coordinate input file (such as INPUT. DAT).

Pavlis et al. (2012) report that the differences between geoid undulations computed from EGM2008 and those computed from independent GPS/levelling data are in the order of 5 to $10 \mathrm{~cm}$. However, higher values of discrepancies have resulted from other studies in specific and limited areas, e.g., RMS (Root Mean Square) of $79 \mathrm{~cm}$ in Saudi Arabia (Alothman et al., 2014).

EGM2008 GIS datasets are available on the Internet: 32 zip files can be downloaded, each containing an ESRI GRID raster dataset of $2.5^{\prime}$ geoid undulation values covering a $45^{\circ} \times 45^{\circ}$ area. Each raster file has a $2.5^{\prime}$ cell size and is a subset of the global $2.5^{\prime} \times 2.5^{\prime}$ grid of pre-computed geoid undulation point values EGM2008-WGS84 (NGAOffice of Geomatics, n.d.). In particular, the value of each $2.5^{\prime}$ raster cell derives from the original pre-computed geoid undulation point value located at the south-west corner of each cell (NGA-Office of Geomatics, n.d.).

For this application, two zip files are considered because the study area is around the 45th parallel that marks the limit of neighbouring datasets. Using ArcGIS, only the area of interest is extracted from them and, considering the different datum of the GNSS PSs, referred to UTMWGS84 (ETRF2000) (Figure 2). At each GNSS PS point the difference between the EGM2008 geoid undulation and the GSS value is computed. 
Using EGM2008 resources available on the Internet concerning a $1^{\prime} \times 1^{\prime}$ global grid of pre-computed geoid undulations, a GIS dataset $1^{\prime} \times 1^{\prime}$ limited to the area of interest is built for this study.

\subsection{Ordinary Kriging interpolator}

The geoid undulation, $\mathrm{N}$, and the horizontal coordinates, $\mathrm{x}$ and $y$, of some control points can be used to determine the local geoid based on an interpolation method, e.g., polynomial regression (M. E. T. I. N. Soycan \& A. R. Z. U. Soycan, 2003; Erol, 2011), Inverse Distance Weighting to a Power (El-Hallaq, 2012), or Kriging (Komarov, Kascheev, \& Zagretdinov, 2008). For example, using a second-degree polynomial as the specific mathematical relation/model, with at least six control points, whose $\mathrm{N}, \mathrm{x}$ and $\mathrm{y}$ are known, the six polynomial coefficients may be computed by defining the exact mathematical relation: this model can be used to obtain the $\mathrm{N}$ value for any location by inputting the horizontal coordinates $\mathrm{x}$ and $\mathrm{y}$ (Das, Samanta, Jana, \& Rosa, 2017).

Ordinary Kriging, one of the most useful geostatistical methods in providing accurate approximations, has supplied good performances for geoid model determination by GPS/levelling data (Soycan, 2013). Recently, Ligas and Kulczycki (2018) used Ordinary Kriging and moving window Kriging on a sphere for local geoid definition.

Using GPS/levelling data, several measured values to be interpolated are necessary: in the case of Izimir Municipality (Turkey), 1148 points were used as input dataset for an area covered by the grid of 12,648 sq km (Soycan, 2013). It is also possible to model the differences between the GPS/levelling undulations and the EGM2008 derived undulations at identified control points and then incorporate the resulting data into the global model (Peprah et al., 2017; Dawod, Mohamed, \& Ismail, 2009). In this case, a smaller number of points can be used, considering that the global model covers the whole area. The aim of this paper is to assess the accuracy of the geoid model resulting by fitting EGM2008 in a local area using a limited number of control points uniformly distributed on the territory, such as GNSS PS. To interpolate undulation differences, the Ordinary Kriging method (Wackernagel, 1995) which is generally appreciated among the Kriging methods for its simplicity and ease to solve, is used in this study.

\subsection{Cross-validation}

Cross-validation is a statistical validation technique used to assess how well an interpolation model performs (Xiao et al., 2016). In other words, it permits to define the accuracy level of predictive values. It involves removing a point from the data to be interpolated, using other points to estimate a value at the location of the removed point, and testing the performance by means of the removed data. The residual, or the difference between the known and estimated point in turn, is computed to evaluate the goodness of the adopted interpolation method (Fasshauer \&
Zhang, 2007). Instead of only one data point, a subset of the starting database can be removed in turn.

Cross-validation indicates a whole class of model evaluation methods. The holdout method is the simplest kind of cross-validation: the dataset is divided into two parts, named the training set and the testing set. The first set is used to determine the interpolation function, the second to calculate the residuals that the chosen interpolator produces in test points (Kohavi, 1995). K-fold cross-validation permits to improve over the holdout method: the dataset is separated into $\mathrm{k}$ subsets, and the holdout method is repeated $\mathrm{k}$ times; each time, one of the $\mathrm{k}$ subsets is chosen as the test set and the other k-1 subsets are used together as a training set (Refaeilzadeh, Tang, \& Liu, 2009).

Cross-validation is useful to evaluate the performance of an exact interpolator such as Ordinary Kriging that does not produce residuals in the given points. It permits to estimate the generalisation error without sacrificing an important amount of data as test points (Weiss \& Kulikowski, 1991; Angulo-Martínez, Lopez-Vicente, VicenteSerrano, \& Beguería, 2009).

$\mathrm{K}$-fold cross-validation is applied in this study. Specifically, the whole dataset is divided into five classes, each of them containing five GNSS PSs. One of them, the class named GNSS PSs 5, contains the "more peripheral" points, i.e., the points that are positioned respectively at higher/lower latitude and longitude. It is included in all training datasets, so to allow the same extension for each model (all values are interpolated and not extrapolated). The remaining four folds are purely random-partitioned. The schematic diagram of the cross-validation is shown in Figure 3 where, for each subset, the identification number (as reported in Table 1) of each GNSS PS included is indicated.

\begin{tabular}{|c|c|c|c|c|}
\hline Class of Stations & $\begin{array}{l}\text { Experi- } \\
\text { ment } 1\end{array}$ & $\begin{array}{l}\text { Experi- } \\
\text { ment } 2\end{array}$ & $\begin{array}{l}\text { Experi- } \\
\text { ment } 3\end{array}$ & $\begin{array}{l}\text { Experi- } \\
\text { ment } 4\end{array}$ \\
\hline $\begin{array}{l}\text { GNSS PSs } 1: 3,14,16 \text {, } \\
18,22\end{array}$ & & & & \\
\hline
\end{tabular}

\section{GNSS PSs 2: 7, 11, 12,}

20,23

GNSS PSs $3: 8,9,15$,

24,25

GNSS PSs 4: 1, 4, 5 ,

13,17

GNSS PSs 5: 2, 6, 10,

19,21

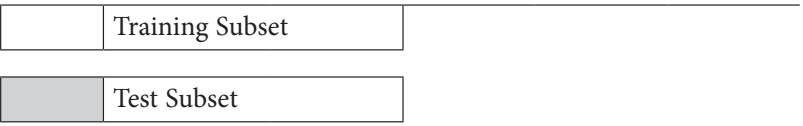

Figure 3. Schematic of the cross-validation: for each subset, the identification number (the same reported in Table 1) of each GNSS PS included is indicated 


\section{Results and discussion}

To determine local geoid model in the considered area, we use Geostatistical Analyst, an extension of ArcGIS version 10.3 by ESRI to generate surfaces from sample data by means of interpolation methods.

Specifically, within this extension, the Geostatistical Wizard is a dynamic set of pages that guides the user through the process of constructing and evaluating the performance of an interpolation model. During the construction phase, the wizard permits to change parameter values and suggests optimised values for each; it also consents to move forward or backward in the process as well as to assess the cross-validation results to see whether the current model is acceptable or some of the parameter values should be modified. The Geostatistical Wizard provides several interpolation methods, both deterministic and geostatistical (Johnston, Ver Hoef, Krivoruchko, \& Lucas, 2001).

The selected Ordinary Kriging method requires, as a first step, the construction of the empirical variogram. In this study, the lag size and the number of intervals into which the range of distances to be analysed is divided are chosen as 15,000 m and 12 respectively. Different attempts are made to approximate the experimental variogram with the theoretical variogram: in this case, the function that best fits the points of the empirical variograms (Oliver \& Webster, 2014) is the Gaussian model.

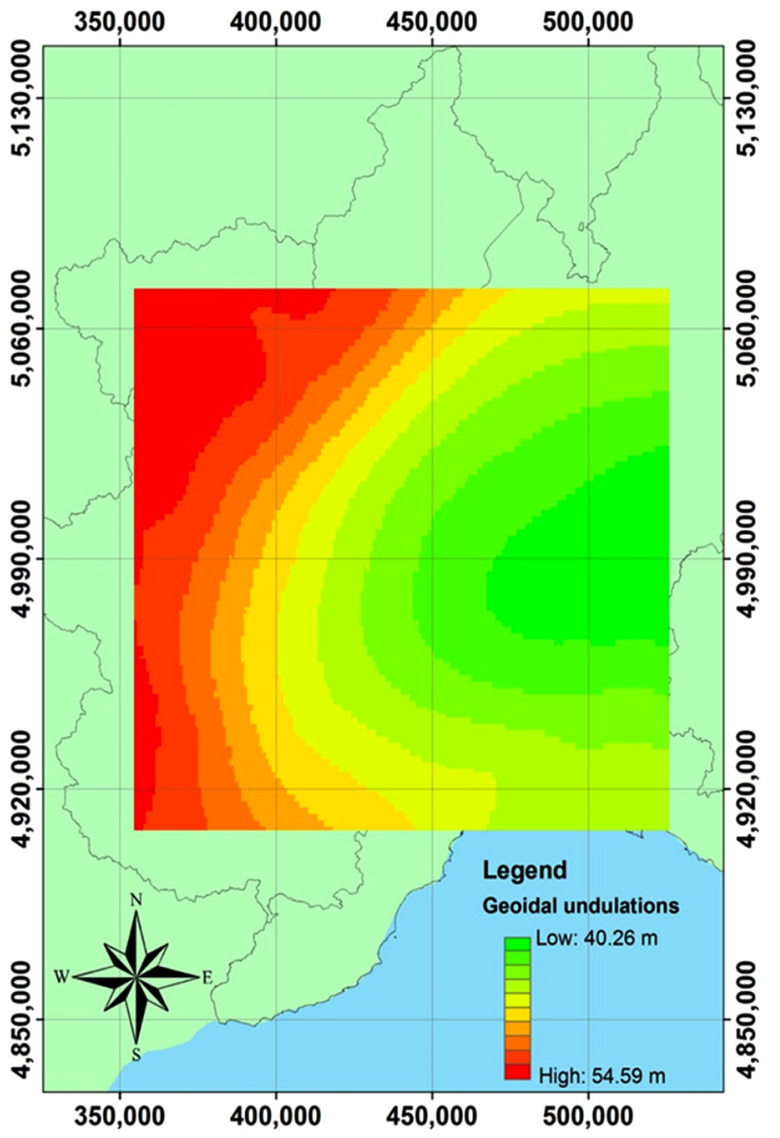

Figure 4 . The final local geoid model (horizontal coordinates are in meters)
Geostatistical Wizard applies cross-validation by sequentially omitting a point and predicting its value using the rest of the data. Statistics on the differences between measured and predicted values serve as diagnostics that indicate whether the model is reasonable for map production. In other words, the best solution is identified by minimizing the error (Dashtpagerdi, Vagharfard, \& Honarbakhsh, 2013).

The result of the Geostatistical Wizard procedure is a prediction map that shows the interpolated values at a very high level of detail. The user may save the resulting model in raster format, selecting the pixel dimensions. Of course, the higher the resolution, the greater the quantitative of stored information, but also the greater the file dimension. A compromise is therefore necessary, taking into account the distance between the sample data.

In this work the differences between the GNSS PS geoidal heights and the corresponding EGM2008 1' $\times 1^{\prime}$ ones are used as a starting dataset for Ordinary Kriging application. The resulting model is summed to the EGM2008 $1^{\prime} \times 1^{\prime}$, obtaining the undulation model $60 \mathrm{~m} \times$ $60 \mathrm{~m}$ shown in Figure 4.

Table 2 reports the statistics of the differences between EGM2008 and GNSS PS geoidal heights. In particular, using a geoid online calculator named GeoidEval (Karney, 2008), undulation interpolated values in the considered points are calculated; thus, in Table 2 are the differences between EGM2008 2.5' $\times 2.5^{\prime}$ and GNSS PS geoidal heights (raw 1), EGM2008 $1^{\prime} \times 1^{\prime}$ and GNSS PS geoidal heights (raw 2), EGM2008 interpolated values (EGM2008 IV) and GNSS PS geoidal heights (raw 3). The interpolated model permits to reduce the errors, but in both cases the results show that the global model (GIS dataset $2.5^{\prime} \times$ $2.5^{\prime}$, GIS dataset $1^{\prime} \times 1^{\prime}$, interpolated values) is not suitable for some local applications.

In fact, subtracting EGM2008 geoidal undulation from GPS ellipsoidal height, the resulting orthometric height is affected by an error unacceptable for geomatics operations at a large scale (1:5000 or less). By contrast, the results show an aspect well known in the literature: compared with local undulations, EGM2008 presents a bias due to the reference point considered for the definition of the zero level in the local area.

Table 2. Statistics of the differences between EGM2008 (2.5' $\times$ $2.5^{\prime}, 1^{\prime} \times 1^{\prime}$, interpolated values) and GNSS PS geoidal heights

\begin{tabular}{|l|c|c|c|c|c|}
\hline \multicolumn{1}{|c|}{ Difference } & $\begin{array}{c}\text { Min } \\
(\mathrm{m})\end{array}$ & $\begin{array}{c}\text { Max } \\
(\mathrm{m})\end{array}$ & $\begin{array}{c}\text { Mean } \\
(\mathrm{m})\end{array}$ & $\begin{array}{c}\text { Standard } \\
\text { deviation } \\
(\mathrm{m})\end{array}$ & $\begin{array}{c}\text { RMS } \\
(\mathrm{m})\end{array}$ \\
\hline $\begin{array}{l}\text { EGM2008 2.5 } \times \\
2.5^{\prime}-\text { GNSS PS }\end{array}$ & 0.059 & 0.999 & 0.534 & 0.220 & 0.578 \\
\hline $\begin{array}{l}\text { EGM2008 1' } \times 1^{\prime}- \\
\text { GNSS PS }\end{array}$ & 0.244 & 0.657 & 0.470 & 0.113 & 0.483 \\
\hline $\begin{array}{l}\text { EGM2008 IV - } \\
\text { GNSS PS }\end{array}$ & 0.298 & 0.608 & 0.472 & 0.086 & 0.480 \\
\hline
\end{tabular}


Because Ordinary Kriging tends to conserve the primary values (changes are introduced only as a result of the model resolution), residuals in the used points (GNSS PS locations) are zero. As a result, cross-validation (its limits notwithstanding) can provide first information on the achieved accuracy. As previously explained, the ArcGIS tool removes one data location and then predicts the associated data using the data at the remaining locations. Statistics on the resulting residuals are shown in Table 3. These results seem to prove a good performance, but further insights are needed.

Table 3. Statistics of the results of the cross-validation provided by ArcGIS tool for the Ordinary Kriging interpolation

\begin{tabular}{|l|c|c|c|c|c|}
\hline & $\begin{array}{c}\text { Min } \\
(\mathrm{m})\end{array}$ & $\begin{array}{c}\text { Max } \\
(\mathrm{m})\end{array}$ & $\begin{array}{c}\text { Mean } \\
(\mathrm{m})\end{array}$ & $\begin{array}{c}\text { Standard } \\
\text { deviation } \\
(\mathrm{m})\end{array}$ & $\begin{array}{c}\text { RMS } \\
(\mathrm{m})\end{array}$ \\
\hline $\begin{array}{l}\text { ArcGIS Cross- } \\
\text { validation } \\
\text { results }\end{array}$ & -0.202 & 0.159 & 0.002 & 0.079 & 0.079 \\
\hline
\end{tabular}

As a consequence, the approach to the cross-validation illustrated in the previous paragraph and based on four experiments, is adopted. In Table 4, the statistics of the cross-validation results are reported. Considering all experiments, the differences between interpolated and measured values vary from $\pm 0.177 \mathrm{~m}$ to $\pm 0.239 \mathrm{~m}$, the standard deviation varies from $0.032 \mathrm{~m}$ to $0.149 \mathrm{~m}$, the mean values vary from $\pm 0.006 \mathrm{~m}$ to $\pm 0.029 \mathrm{~m}$, and the RMS varies from $0.033 \mathrm{~m}$ to $0.149 \mathrm{~m}$.

Table 4. Statistics of the results of the cross-validation applied to the local geoidal height model obtained with the Ordinary Kriging interpolation

\begin{tabular}{|l|c|c|c|c|c|}
\hline & Min (m) & Max (m) & $\begin{array}{c}\text { Mean } \\
(\mathrm{m})\end{array}$ & $\begin{array}{c}\text { Standard } \\
\text { deviation } \\
(\mathrm{m})\end{array}$ & $\begin{array}{c}\mathrm{RMS} \\
(\mathrm{m})\end{array}$ \\
\hline $\begin{array}{l}\text { Expe- } \\
\text { riment 1 }\end{array}$ & -0.135 & 0.109 & 0.001 & 0.090 & 0.090 \\
\hline $\begin{array}{l}\text { Expe- } \\
\text { riment 2 }\end{array}$ & -0.022 & 0.080 & 0.029 & 0.041 & 0.050 \\
\hline $\begin{array}{l}\text { Expe- } \\
\text { riment 3 }\end{array}$ & -0.047 & 0.033 & -0.006 & 0.032 & 0.033 \\
\hline $\begin{array}{l}\text { Expe- } \\
\text { riment 4 }\end{array}$ & -0.177 & 0.239 & 0.011 & 0.149 & 0.149 \\
\hline
\end{tabular}

These results seem to attest to a good performance of the Ordinary Kriging interpolator, but more reliable are tests on check points (CPs) that are not included in the dataset used. Fifty CPs in the study area are therefore considered to assess the model accuracy and the limits to its practical use. They are selected by Geodetic networks (realised by the local administrations, i.e., Piemonte, Valle d'Aosta, Lombardia and Liguria Region) to provide uniform coverage of the study area, as shown in Figure 5.

In the monograph of each Geodetic Point, all useful data are included. In particular, both the ellipsoidal and ortometric heights are present, the first resulting by accurate GPS survey, the latter measured by levelling or calculated using the accurate local geoid ItalGeo2005 whose differences compared to EGM2008 are well known in literature (Barzaghi et al., 2016). Differences between the ellipsoidal and orthometric heights are calculated to achieve geoid undulations. Table 5 shows the statistics of the test results. These results show the presence of a bias in EGM2008 due to the reference point considered for the definition of the zero level in the local area. The mean value $(0.483 \mathrm{~m})$ is similar to that previously resulted (0.472 m). EGM2008 should therefore be performed using a vertical translation, to bring the model near the GNSS PS undulation values; in other words, the bias must be subtracted from the original value of each undulation (Maglione, Parente, \& Vallario, 2018). The statistics of the differences between the EGM2008 bias-corrected and CPs geoidal heights are shown in Table 6.

Comparing the statistics reported in Table 5 and Table 6, the model obtained performing EGM2008 with GNSS PS undulation values is more accurate than the EGM2008, as well as from the bias-corrected EGM2008. In fact, it permits to achieve an RMS value of $\pm 0.112 \mathrm{~m}$, while residuals vary from $\pm 0.251 \mathrm{~m}$ to $0.265 \mathrm{~m}$. The bias-corrected EGM2008 is more accurate than EGM2008, but presents higher values of standard deviation and RMS as well as a larger range of residual values than the proposed model.

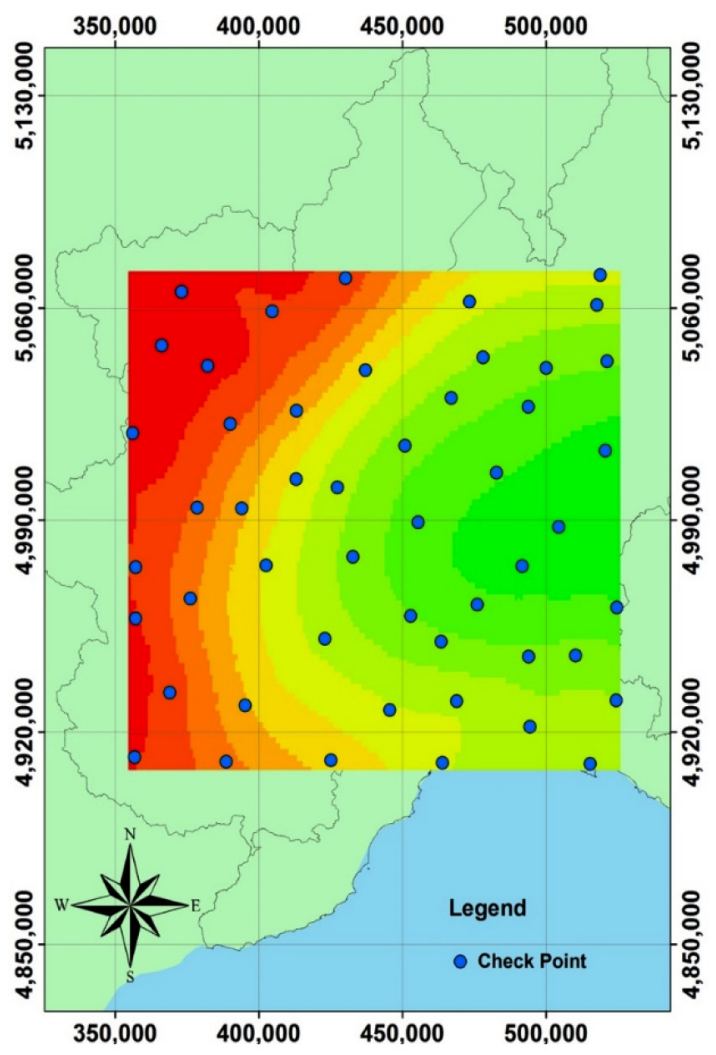

Figure 5. The distribution of the 50 check points in the study area 
Table 5. Statistics of the differences between the local model and check point (CP) geoidal heights compared with those obtained for EGM2008

\begin{tabular}{|l|c|c|c|c|c|}
\hline & $\begin{array}{c}\text { Min } \\
(\mathrm{m})\end{array}$ & $\begin{array}{c}\text { Max } \\
(\mathrm{m})\end{array}$ & $\begin{array}{c}\text { Mean } \\
(\mathrm{m})\end{array}$ & $\begin{array}{c}\text { Standard } \\
\text { deviation } \\
(\mathrm{m})\end{array}$ & $\begin{array}{c}\text { RMS } \\
(\mathrm{m})\end{array}$ \\
\hline $\begin{array}{l}\text { Local } \\
\text { model - } \\
\begin{array}{l}\text { CPs geoidal } \\
\text { heights }\end{array}\end{array}$ & -0.265 & 0.251 & 0.003 & 0.112 & 0.112 \\
\hline $\begin{array}{l}\text { EGM2008 } \\
\text { CPs geoidal } \\
\text { heights }\end{array}$ & 0.048 & 0.777 & 0.483 & 0.132 & 0.501 \\
\hline
\end{tabular}

Table 6. Statistics of the differences between EGM2008 bias-corrected and CPs geoidal heights

\begin{tabular}{|l|c|c|c|c|c|}
\hline & $\begin{array}{c}\text { Min } \\
(\mathrm{m})\end{array}$ & $\begin{array}{c}\text { Max } \\
(\mathrm{m})\end{array}$ & $\begin{array}{c}\text { Mean } \\
(\mathrm{m})\end{array}$ & $\begin{array}{c}\text { Standard } \\
\text { deviation } \\
(\mathrm{m})\end{array}$ & $\begin{array}{c}\text { RMS } \\
(\mathrm{m})\end{array}$ \\
\hline $\begin{array}{l}\text { (EGM2008- } \\
\text { bias) - CPs } \\
\text { geoidal } \\
\text { heights }\end{array}$ & -0.435 & 0.294 & 0.0004 & 0.132 & 0.132 \\
\hline
\end{tabular}

As a result, it is possible to use the proposed model to produce from a GPS dataset contours for large-scale mapping. In fact, the USGS (United States Geological Survey) Map Accuracy Standard requires that not more than 10\% of the elevations tested shall be in error by more than onehalf of the contour interval; therefore, because in 5 points ( $10 \%$ of CPs) it presents residuals higher than $0.20 \mathrm{~m}$, the proposed model is useful to contour data with a contour interval of $0.40 \mathrm{~m}$ (scale 1:2000).

\section{Conclusions}

This study confirms that global geoid models presenting in local areas accuracy values that are not suitable for applications at large scale may be performed using accurate undulations values, e.g., derived by GPS/levelling.

The experiments carried out on an area located in Northwestern Italy also demonstrate that a limited number of points can contribute to improve the accuracy of the resulting model, if appropriately chosen and used. In particular, considering an area of about $28,000 \mathrm{sq} \mathrm{km}$, a starting dataset of 25 GNSS PSs permits to decrease of 78\% the RMS of the undulation residuals in $50 \mathrm{CPs}$ supplied by the EGM2008 $1^{\prime} \times 1^{\prime}$. The adopted approach is based on two steps: firstly, the differences between the GNSS PS geoidal heights and the corresponding EGM2008 $1^{\prime} \times 1^{\prime}$ ones are interpolated using Ordinary Kriging; the resulting model is then summed to the EGM2008 $1^{\prime} \times 1^{\prime}$ to obtain the undulation model (in this study a grid $60 \mathrm{~m} \times$ $60 \mathrm{~m}$ is adopted).

The resulting model is better than the bias-corrected EGM2008, even if the improvement is limited to a few centimetres. By using the calculated geoid model to derive orthometric heights from ellipsoidal heights in the considered area, the tests indicate an RMS value of 0.112 $\mathrm{m}$, with residuals from $\pm 0.251 \mathrm{~m}$ to $0.265 \mathrm{~m}$. In accordance with the USGS Map Accuracy Standard, it is possible to use this model for large-scale map applications, and it permits the use of a GPS dataset to produce contours suitable for a scale of 1:2000.

In this work, to demonstrate the benefit of using these freely available data appropriately integrated in EGM2008, only a GNSS PS coordinate dataset is considered. The geoid model accuracy can also be improved using other datasets, e.g., levelling network data that in some cases are accessible free of charge. An interesting development of this study should be to test the accuracy variability of the resulting model by increasing the number of the dataset records.

Another aspect to be considered should be the comparison of different interpolation methods, e.g., Inverse Distance Weighting to a Power or second-degree polynomial.

Ultimately, the proposed model is not useful for institutional operations where the official local geoid (ItalGeo2005) is required as well, as in every case this requires very high accuracy. Nevertheless, it can support studies and applications where GPS datasets are available and orthometric heights are necessary, but with accuracy higher than a global model and lower than the official local model. This category includes some GIS applications at large scale that require elevation data, e.g., some DTM constructions, visual impact assessment of new opera on the neighbourhood landscape or screening of areas useful for wind farms.

\section{References}

Alothman, A., Bouman, J., Gruber, T., Lieb, V., Alsubaei, M., Alomar, A., Fuchs, M., \& Schmidt, M. (2014). Validation of Regional geoid models for Saudi Arabia using GPS/levelling data and GOCE models. Gravity, Geoid and Height Systems, IAG Symposia, 141, 193-199.

Angulo-Martínez, M., Lopez-Vicente, M., Vicente-Serrano, S. M., \& Beguería, S. (2009). Mapping rainfall erosivity at a regional scale: a comparison of interpolation methods in the Ebro Basin (NE Spain). Hydrology and Earth System Sciences, 13(10), 1907-1920.

https://doi.org/10.5194/hess-13-1907-2009

Barzaghi, R., Borghi, A., Carrion, D., \& Sona, G. (2007). Refining the estimate of the Italian quasigeoid. Bollettino di Geodesia e Scienze Affini, 3, 145-160.

Barzaghi, R., Carrion, D., Pepe, M., \& Prezioso, G. (2016). Computing the deflection of the vertical for improving aerial surveys: a comparison between EGM2008 and ITALGEO05 estimates. Sensors, 16(8), 1168.

https://doi.org/10.3390/s16081168

Belfiore, O. R., \& Parente, C. (2016). Comparison of different algorithms to orthorectify WorldView-2 satellite imagery. Algorithms, 9(4), 67. https://doi.org/10.3390/a9040067

Biagi, L., Caldera, S., Capra, A., Castagnetti, C., \& Sansò, F. (2008). Densification of IGS/EPN by local permanent networks: sensitivity of results with respect to the adjustment choices. In Bulletin of Geodesy and Geomatics. Istituto Geografico Militare, Firenze (Italy). 
Das, R. K., Samanta, S., Jana, S. K., \& Rosa, R. (2017). Polynomial interpolation methods in development of local geoid model. The Egyptian Journal of Remote Sensing and Space Science. https://doi.org/10.1016/j.ejrs.2017.03.002

Dashtpagerdi, M. M., Vagharfard, H., \& Honarbakhsh, A. (2013). Application of cross-validation technique for zoning of groundwaterlevels in Shahrekord plain. Agricultural Sciences, 4(7), 329-333. https://doi.org/10.4236/as.2013.47047

Dawod, G. M., Mohamed, H. F., \& Ismail, S. S. (2009). Evaluation and adaptation of the EGM2008 geopotential model along the Northern Nile Valley, Egypt: Case study. Journal of Surveying Engineering, 136(1), 36-40. https://doi.org/10.1061/(ASCE)SU.1943-5428.0000002

Di Pasquale, A., Nico, G., Pitullo, A., \& Prezioso, G. (2018). Monitoring strategies of earth dams by ground-based radar interferometry: how to extract useful information for seismic risk assessment. Sensors, 18(1), 244.

https://doi.org/10.3390/s18010244

El-Hallaq, M. A. (2012). Development of a local GPS-leveling geoid model for the Gaza Strip area. International Journal of Emerging Technology and Advanced Engineering, 2, 268-273.

Erol, B. (2011). An automated height transformation using precise geoid models. Scientific Research and Essays, 6(6), 13511363. https://doi.org/10.5897/SRE10.1119

Errico, A., Angelino, C. V., Cicala, L., Podobinski, D. P., Persechino, G., Ferrara, C., Lega, M., Vallario, A., Parente, C., Masi, G., Gaetano, R., Scarpa, G., Amitrano, D., Ruello, G., Verdoliva, L., \& Poggi, G. (2014). SAR/multispectral image fusion for the detection of environmental hazards with a GIS. In Proceedings of SPIE - Earth Resources and Environmental Remote Sensing/GIS Applications V, 9245. International Society for Optical Engineering. https://doi.org/10.1117/12.2066476

Falchi, U. (2017). Spatial data: from cartography to geodatabase. Geodesy and Cartography, 43(4), 142-146. https://doi.org/10.3846/20296991.2017.1412613

Fasshauer, G. E., \& Zhang, J. G. (2007). On choosing "optimal” shape parameters for RBF approximation. Numerical Algorithms, 45(1-4), 345-368. https://doi.org/10.1007/s11075-007-9072-8

Featherstone, W. E., Dentith, M. C., \& Kirby, J. F. (1998). Strategies for the accurate determination of orthometric heights from GPS. Survey Review, 34(267), 278-296.

https://doi.org/10.1179/sre.1998.34.267.278

Fotopoulos, G., Kotsakis, C., \& Sideris, M. G. (2003). How accurately can we determine orthometric height differences from GPS and geoid data? Journal of Surveying Engineering, 129(1), 1-10. https://doi.org/10.1061/(ASCE)0733-9453(2003)129:1(1)

Johnston, K., Ver Hoef, J. M., Krivoruchko, K., \& Lucas, N. (2001). Using ArcGIS ${ }^{\text {mo }}$ geostatistical analyst. Redlands: ESRI.

Kaplan, E., \& Hegarty, C. (2005). Understanding GPS: principles and applications (p. 683). Artech house.

Karney, C. (2008). Online geoid calculations using the GeoidEval utility. Retrieved from https://geographiclib.sourceforge.io/ cgi-bin/GeoidEval

Kohavi, R. (1995). A study of cross-validation and bootstrap for accuracy estimation and model selection. Proceedings of IJCAI, 14(2), 1137-1145.

Komarov, R. V., Kascheev, R. A., \& Zagretdinov, R. V. (2008). Geoid determination by GPS/leveling method in the Republic of Tatarstan. Georesources, 43(2), 43-45.

Lemoine, F. G., Kenyon, S. C., Factor, J. K., Trimmer, R. G., Pavlis, N. K., Chinn, D. S., \& Wang, Y. M. (1998). The development of the joint NASA GSFC and the National Imagery and Mapping Agency (NIMA) Geopotential Model EGM96 (Tech- nical Report). Retrieved from https://ntrs.nasa.gov/archive/ nasa/casi.ntrs.nasa.gov/19980218814.pdf

Ligas, M., \& Kulczycki, M. (2018). Kriging and moving window kriging on a sphere in geometric (GNSS/levelling) geoid modelling. Survey Review, 50(359), 155-162. https://doi.org/10.1080/00396265.2016.1247131

Maglione, P., Parente, C., Santamaria, R., \& Vallario, A. (2014). Modelli tematici 3D della copertura del suolo a partire da DTM e immagini telerilevate ad alta risoluzione WorldView-2. Rendiconti Online della Società Geologica Italiana, 30, 33-40 (in Italian). https://doi.org/10.3301/ROL.2014.08

Maglione, P., Parente, C., \& Vallario, A. (2018). Accuracy of global geoid height models in local area: tests on campania region (Italy). International Journal of Civil Engineering and Technology, 9(3), 1049-1057.

Marti, U. (2007). Comparison of high precision Geoid Models in Switzerland. Dynamic Planet, IAG Symposia, 130, 377-382. https://doi.org/10.1007/978-3-540-49350-1_55

NGA/NASA. (n.d.). EGM96, N=M=360 Earth Gravitational Model available online. Retrieved from http://earth-info.nga. mil/GandG/wgs84/gravitymod/egm96/egm96.html

NGA-Office of Geomatics. (n.d.). NGA/NASA EGM96. Retrieved from http://earth-info.nga.mil/GandG/update/index.php

Oliver, M. A., \& Webster, R. (2014). A tutorial guide to Geostatistics: computing and modelling variograms and kriging. Catena, 113, 56-69. https://doi.org/10.1016/j.catena.2013.09.006

Pavlis, N. K., Holmes, S. A., Kenyon, S. C., \& Factor, J. K. (2008). EGM2008: An overview of its development and evaluation. In IAG International Symposium, GGEO, 2327. National Geospatial-Intelligence Agency, USA.

Pavlis, N. K., Holmes, S. A., Kenyon, S. C., \& Factor, J. K. (2012). The development and evaluation of the Earth Gravitational Model 2008 (EGM2008). Journal of Geophysical Research: Solid Earth, 117(B4). https://doi.org/10.1029/2011JB008916

Pepe, M., Prezioso, G., \& Santamaria, R. (2015). Impact of vertical deflection on direct georeferencing of airborne images. Survey Review, 47(340), 71-76. https://doi.org/10.1179/1752270614Y.0000000087

Peprah, M. S., Ziggah, Y. Y., \& Yakubu, I. (2017). Performance evaluation of the Earth Gravitational Model 2008 (EGM2008) - a case study. South African Journal of Geomatics, 6(1), 47-72. https://doi.org/10.4314/sajg.v6i1.4

Pugh, D. T. (1987). Tides, surges and mean sea-level (p. 486). John Wiley \& Sons.

Rapp, R. H., \& Wang, Y. M. (1993). Geoid undulation differences between Geopotential models. Surveys in Geophysics, 14(4-5), 373-380. https://doi.org/10.1007/BF00690565

Refaeilzadeh, P., Tang, L., \& Liu, H. (2009). Cross-validation. In Encyclopedia of database systems (pp. 532-538). Boston: Springer US.

Shen, W., \& Han, J. (2013). Improved geoid determination based on the shallow-layer method: a case study using EGM08 and CRUST2.0 in the Xinjiang and Tibetan Regions. Terrestrial, Atmospheric \& Oceanic Sciences, 24(4), 591-604. https://doi.org/10.3319/TAO.2012.11.12.01(TibXS)

Soycan, M. (2013). Analysis of geostatistical surface model for GPS height transformation: a case study in Izmir territory of Turkey. Geodetski Vestnik, 57(4), 702-718. https://doi.org/10.15292/geodetski-vestnik.2013.04.702-718

Soycan, M. E. T. I. N., \& Soycan, A. R. Z. U. (2003). Surface modeling for GPS-levelling geoid determination. Newton's Bulletin, 1, 41-52. Retrieved from http://www.isgeoid.polimi. it/Newton/Newton_1/soycan.pdf 
Van der Marel, H. (2014). Reference systems for surveying and mapping. Retrieved from http://gnss1.tudelft.nl/pub/vdmarel/ reader/CTB3310_RefSystems_1-2a_print.pdf

Wackernagel, H. (1995). Multivariate Geostatistics: an introduction with applications (p. 307). Berlin, Heidelberg: Springer. https://doi.org/10.1007/978-3-662-03098-1

Weiss, S. M., \& Kulikowski, C. A. (1991). Computer systems that learn: classification and prediction methods from statistics, neural nets, machine learning, and expert systems (p. 223). Morgan Kaufmann.

Xiao, Y., Gu, X., Yin, S., Shao, J., Cui, Y., Zhang, Q., \& Niu, Y. (2016). Geostatistical interpolation model selection based on ArcGIS and spatio-temporal variability analysis of groundwater level in piedmont plains, Northwest China. SpringerPlus, $5(1), 425$.

https://doi.org/10.1186/s40064-016-2073-0 